\title{
Competitive Recruitment and Ethical Leadership
}

\author{
SUARLAN \\ Badan Informasi Geospasial (The Indonesian Geospatial Agency) \\ Bureau of Planning, Human Resources and Legal \\ Bogor, Indonesia \\ (suarlan@big.go.id)
}

\begin{abstract}
Competitive recruitment brings benefits for an organization by enabling it to improve its performance. Employees who are recruited by competitive recruitment should have better knowledge and skills. In their daily activities, these employees will interact with their leaders. This interaction will result in many perceptions on the part of the employees about the leaders. One of these perceptions will be about ethical leadership. Employees perceive how the leaders deal with ethical matters. Competitive recruitment should bring a competitive advantage to an organization. However, there is a gap between the effects of competitive recruitment on ethical leadership. This qualitative study would like to answer the effects of competitive recruitment on employees' perceptions of ethical leadership.
\end{abstract}

Keywords --- recruitment, ethical leadership, civil servants, perception

\section{Introduction}

In 2013, Indonesian football experienced a major triumph. The Indonesian national team defeated Vietnam in the final of the AFF U-19 Championship (Tempo, 2013). This meant that Indonesia had become the best U-19 football team in South East Asia. The victory was very emotional for many Indonesians as the country spent years waiting to lift up a trophy in a football competition (Tempo, 2013). The history dates back to 1991, the year in which Indonesia achieved its last success in football (Bellford,
2011). In 2013, the person who received most praise as a hero was the coach, Indra Sjafri. Sjafri employed a very different method when recruiting his players. He went to remote areas in search of new players (Maksum, 2014, p. 66). This was the key to the success of the Indonesian U-19 team because all players had been given the same opportunity to get selected for the national team. In this case, it could be argued that this competitive recruitment process was the most important factor contributing to the victory of the Indonesian U-19 national team. This is comparable to an organization where there are numerous benefits that a competitive recruitment process can offer. The employees recruited during a competitive recruitment process should bring competitive advantages for an organization (Williamson, Cable, \& Aldrich, 2002).

Another factor that determines the success of an organization is its leader. A leader acts as an important driving force as he/she acts as a guide for the employees (Brown, Treviño \& Harrison, 2005, p. 117). The leader must create a standard for how employees should behave that is in line with the organization's goals. In this aspect, the leader is a central source of instruction (Brown, Treviño \& Harrison, 2005, p. 117). In other words, if a leader exerts a positive influence, then the employees will give a satisfactory performance. However, if the leadership is not strong and exemplary, the employees may not perform as well. A perfect combination between competitive recruitment and strong leadership is needed. I would argue that an employee who is recruited in a competitive process may demand more from 
his/her leader. To this end, it would be interesting to see what action a leader should take. This also relates to the ethical leadership of a leader in an organization.

Additionally, it is important that a leader is chosen using a competitive promotion process. In a government organization context, unfair promotion process results in a country in a corrupt condition (Blunt, Turner, \& Lindroth, 2012). Consequently, the government is ineffective and inefficient. In practice, a corrupt government is not only due by an unfair promotion process, as a strong patronage mechanism also contributed to the problem (Blunt, Turner, \& Lindroth, 2012). Indonesia is an example where bureaucracy has suffered from strong patronage and an unfair promotion process (Blunt, Turner, \& Lindroth, 2012). As a consequence of the unfair promotion process, leaders who lack skill and knowledge may have been selected for promotion. As a result, employees, especially those who are recruited in a competitive process, might also have negative perceptions of these leaders. This is because the employees may feel that they have more capability and knowledge to do the job (Williamson, et. al, 2002). Consequently, these employees might have their own perceptions about their interaction with the leaders, especially about ethical leadership. However, the correlation between competitive recruitment and ethical leadership still remains unclear. Therefore, this paper proposes research into this connection by asking the following question:

What are the effects of competitive recruitment on the perception of ethical leadership?

The study is relevant for two reasons. First, theoretically the study would like to examine the relationship between competitive recruitment and ethical leadership. Thus, the study will make a contribution to leadership theory. Second, there is a practical benefit of this study in assisting BIG (Badan Informasi Geospasial/Geospatial
Information Agency) for leader assessment. The study will contribute data to BIG by evaluating and assessing managers' and supervisors' performance as perceived by their staff. This could benefit the organization in two ways. First, it evaluates a current leader's ethics according to the perception of civil servants. These data could be used by the head of BIG when considering further steps which could involve a promotion or demotion for leaders. Second, talking with grassroots staff would result in an expectation from the leaders which the study would reveal. Therefore, the head of BIG could adjust the requirements for promotion process.

BIG is a survey and mapping institution. According to the Indonesian law 4/2011, BIG is responsible in providing a base map for infrastructure planning. BIG's main core business requires a deep knowledge in geodesy, geography, and computer systems. BIG's organization is divided into 12 departments, 31 divisions, and 22 subdivisions. This means that there are 31 managers and 22 supervisors. The institution has a lot of experience in the recruitment process. This experience will be discussed further in the findings section.

\section{Theoretical Framework}

First, we start with recruitment and selection. These are the processes of searching for potential employees for an organization. A further definition is given by Barber (1998 in Breaugh and Starke, 2000) who says that "recruitment includes those practices and activities carried on by the organization with the primary purpose of identifying and attracting potential employees". The employee should have a potential value that could support an organization. Subsequently, the selection process should be fair and competitive in order to get the most suitable and valuable employees. In future, a competitive recruitment output would be employees who are expected to bring the organization a more competitive edge.

Moreover, research into ethical leadership is not new research. Ethical leadership is also related to employees' trust in the leader (van den Akker, et. al, 2009). This study follows 
the definition of ethical leadership as given by Brown, Treviño, and Harrison (2005, p. 120) who state that "the demonstration of normatively appropriate conduct through personal actions and interpersonal relationships, and the promotion of such conduct to followers through two-way communication, reinforcement, and decisionmaking". Thus, ethical leaders should give an example of normative conduct, e.g. in relation to honesty and trustworthiness. Another definition characterizes ethical leaders as "honest, caring, and principled individuals who make fair and balanced decisions" (Brown \& Treviño, 2006, p. 597). To see whether or not a leader is honest and caring, frequent interaction is needed between the leader and his/her staff. Leaders who fit most accurately with this definition are leaders at middle level such as at a manager or supervisor level. These leaders have closer interactions with staff than leaders at top level management. The interaction may set benchmarks which use reward and punishment to monitor whether standards are followed (Brown \& Treviño, 2006, p. 597).

According to the above-mentioned definition, ethical leadership emphasizes personal characteristics as the first variable. Despite this, Brown et. al (2005) feel that normatively appropriate is a vague term. However, I would say that a general understanding about care, honesty, trustworthiness, or fairness can be developed in leaders as a consequence of their relationship with employees. Brown and Treviño (2006) suggest that the personality characteristics which relate to ethical leadership are agreeableness, conscientiousness, and neuroticism (2006, p. 603). These three features have different roles in determining ethical leadership. As a result of this, Brown and Trevino argue that agreeableness is the strongest trait for personality characteristics (2006, p. 602). The concept of agreeableness is defined as a "tendency to be trusting, altruistic, and cooperative" (Brown and Treviño, 2006, p. 602). The definition shows that in the daily relationship between a leader and staff, trust is very important. If there is strong sense of trust in an organization, all actors will cooperate very well. Consequently, employees will give a satisfactory performance. Conscientiousness relates to how carefully the individual acts when making plans, exercising self-control, practising good organization skills and reliability (Brown and Treviño, 2006, p. 603). Therefore, a leader who is a highly conscientious individual is more likely to be seen as an ethical leader (Brown \& Treviño, 2006). Neuroticism is the leader's tendency to have negative reactions (such as anger), emotional responses, fear, and anxiety (Brown \& Treviño, 2006, p. 603). When experiencing a negative or disappointing result or performance, leaders may express their feelings. Consequently, a leader may be angry or emotional. However, a leader also needs to maintain a good relationship with other members of staff.

Other variables according to the definition of ethical leadership are two-way communication, reinforcement, and decisionmaking. There should be an on-going conversation between leaders and employees. This involves the leader communicating effectively with the staff, while also giving the staff a fair opportunity to speak. Additionally, reinforcement relates to ethical standards which are set by the leader. Ethical conduct being rewarded by the leader and punishment for those employees who are not meeting the standards that have been set (Gini, 1998 and Treviño et, al, 2003 in Brown et al., 2005). Decision-making is related to the leader's need to think about the consequences of the decision that has made.

\section{Expectation}

An effective collaboration should exist between competitive recruited employees and ethical leaders. Also, there should be a meaningful interaction between employees who were recruited in a competitive way and their leaders. Competitive recruited staff are expected to have more competitive skills and knowledge than others (Williamson, et. al, 2002). Consequently, competitive recruited employees may be more critical of their leader. Therefore, they are 
expected to have negative perceptions of ethical leadership. Thus the study expects to examine the following hypothesis:

\section{$\mathrm{H} 1$ : Competitive recruitment will have a negative impact on perceptions of ethical leadership.}

On the other hand, employees who are not recruited competitively may have different perceptions of ethical leadership. According to the hypothesis, the following model could be described:

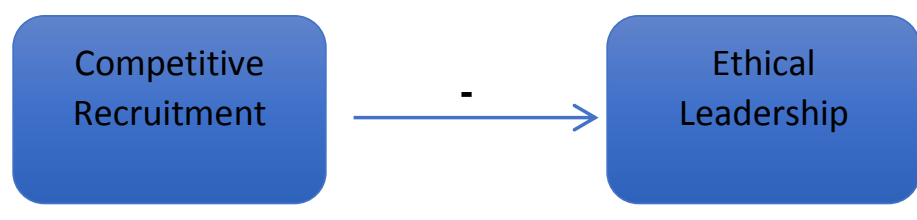

\section{Method}

The study will look at evidence of ethical leadership in Indonesian bureaucracy. To do this, data will be collected by talking to civil servants about how they perceive their leaders' ethics. Due to doubtful processes in the past two years, I will focus on leaders who were promoted between 2014 and 2015. Thus making the concept of ethical leadership more relevant by assessing leaders who have frequent interaction with their staff (Brown \& Treviño, 2006). Therefore, the study will focus on leaders at the level of manager and supervisor. The first step will be to identify how many supervisors and managers were promoted in the timeframe. Once the number of supervisors and managers who were promoted has been determined, the study will then collect data by talking to civil servants who are under the supervision of those leaders.

BIG has been doing competitive recruitment since 2002 (BIG, n.d), so another key step to the study will be to identify civil servants who were recruited after 2002. In this instance, civil servants will be selected randomly. To get additional insights, the study will then collect further data by talking to civil servants who were recruited before 2002, in order to compare perceptions about ethical leadership between the two groups.

Since 2014, 15 managers and supervisors have been promoted in BIG. However, in April 2017, there was another succession process as a result of which not all of them kept their previous positions. Therefore, only 7 leaders were selected for the research. These 7 leaders are four managers and three supervisors who were not impacted by the last succession in April 2017. Interviews were conducted with the staff of these leaders. In total, 13 civil servants participated in the interviews. These civil servants have been divided into those who experienced competitive recruitment and those who did not. The interview process took place between 10 and 24 May 2017.

This study follows questions posed by Brown et al. (2005) and van den Akker et al. (2009) in studying ethical leadership. The questions to be asked of the staff include "What do you think about your leader's honesty?', "How does the leader show care for the employee?", "How far can the leader be trusted?", "How well does the leader listen to what employees have to say?", or "How does the leader discipline employees who violate ethical standards?" These questions were asked during semi-structured interviews which allow for more flexibility so that different questions can be raised during the interviews.

For the analysis part, the data will be processed using the NVIVO program. The interviews are coded into several themes such as personal characteristics, communication, and reinforcement.

\section{Findings}

Recruitment in BIG has transformed from a noncompetitive recruitment to a more competitive recruitment process. There are many reasons why the unfair recruitment process developed. First, by not announcing the opportunity to the public, the recruitment process became unfair. Current 
employees were the only people to receive the information. Thus, applicants who were engaged in the recruitment process had close relationships with current employees, e.g. they were family or friends. This mean that BIG could not accurately choose the best candidate for the job. Consequently, the level of competitiveness for recruitment was not high.

Similarly, recruitment in BIG was unfair because of the existence of temporary employees who are referred to as "honorers" within the organisation. In the past, BIG recruited honorers regularly. Although the necessity of recruiting honorers is still doubtful, the recruitment method was not fair either. Thus, when BIG needed to recruit permanent employees or civil servants, the opportunity was first given to the honorers. Ultimately, all honorers were accepted into the role of civil servants. This experience shows that the recruitment method of promoting honorers contributed to non-competitive recruitment.

Moreover, the intervention by public officials also contributed to the unfair recruitment process. It was believed that public officials had the power to determine who passed the recruitment test. Fortunately, since 2002, the public officials cannot intervene in the process.

BIG has been trying to improve the recruitment process. They intend to realize a more competitive recruitment. According to the interviewees, the recent recruitment methods have seen a lot of improvements, for example more sequence tests, the computer-assisted test, and more difficult questions. As a result, the different grades of each applicant were very close.

Another improvement is the growing popularity of the BIG as an institution. Consequently, the number of applicants has been increasing over the years. This is advantageous for BIG as it allows them to select the best candidate who fits the requirements best. These examples show that recruitment in BIG is more competitive than in the past.

\section{Competitive Recruitment and Ethical Leadership}

Competitive recruitment has had several effects on ethical leadership. The perception of BIG's civil servants about interaction with their leaders reveals that there is a relationship between competitive recruitment and ethical leadership. Some interesting facts have been uncovered by comparing the answers of the civil servants who have experienced competitive recruitment and those who have experienced non-competitive recruitment.

The first aspect that was criticized by the interviewees is the promotion process. Some leaders were promoted by a questionable process. Some interviewees think that the process of promotion was not transparent and fair. Therefore, it seemed that at first some leaders were not the right person for their new position. Some of them adapted very well to the position; however, some others did not. Controversies were caused because of discrepancies between the educational background of the leaders and the job requirements, lack of necessary skills, or having a double position in another unit. This meant that the civil servants were faced with difficulties in their work.

“...His experience was in the (NAME of FIELD), now he has to deal with IT problems. I think it would be much better if he had an IT background so that we can discuss particular problems easily. He would know about technological trends in the future and could use this in forming a new vision." (Marco, transcript p. 26)

In this case, some civil servants also think that in the promotion process the educational background of the leader should be a major consideration. Moreover, the leader's ability is also questioned by the civil servants. For instance, there is a leader whose educational background does not match with his level of responsibility. Consequently, the leader does not display good managerial skills. 
"I think it was more based on the seniority list and educational background. The top-level leader does not look at whether there is a change in the business process or organizational values. .... So that I think it was more because of seniority". (Janneke, transcript, p. 31)

This creates tension between leaders and subordinates. The subordinates feel that leaders should perform better because the BIG has upgraded its missions and values. The examples show that competitive recruitment leads to very high expectations regarding a fair promotion process which leads to perceptions about the conscientiousness of the leader.

Second, there is also a difference in the perception of personal characteristics. Personal characteristics include care, honesty, and trust. The study reveals that the way leaders care about the staff is mostly in relation to their work. Some competitive recruited staffs think that the only thing leaders care about is related to their work. The leaders are more caring if staffs are absent.

"For example about our presence in the office. If we are absent from the office, he will contact us, why didn't we come to the office". (Wendy, transcript, p. 23)

"If we are absent, he will start looking for us. Asking about our condition, what had happened". (Marco, transcript, p. 26)

Interestingly, for competitive recruited staff, the leader should be more caring about civil servants. The leader should not only care when the staff are absent. Civil servants expect the leader to care about the staff on a personal level.

“Actually he doesn't really care. He just cares about our work. He never cares about us as people, but just as his staff.". (Wesley, transcript, p. 38)

Furthermore, competitive recruited staff also measure a leader's level of care. The level also relates to the substance of the work.
"On a scale of 1 to 10, I give him 4. My leader only cares about the financial aspects of our work. For example, about how much did we spend....". (Willemin, transcript, p. 41)

Differently, non-competitive recruited staffs mostly think that it is enough that their leaders care by asking why staff were absent. These staffs do not expect more personal care from their leaders.

In addition, civil servants think that the best way to know if a leader is honest or not is in relation to money and facilities. According to civil servants, their perception of their leader's honesty is good if they do not ask for too much money and/or privileges in relation to their job. Consequently, interaction in this matter is not positive.

"He is an honest guy. Personally I don't have problem with him. But as a professional I just don't believe him. Especially if we deal with money." (Wesley, transcript, p. 38)

"Personally, he is honest. But it is should be one package, honest as a person and honest as a professional. In fact, there is a situational practice." (Janneke, transcript, p. 10)

From the quotes, there is a different perception as $\mathrm{s}$ professional which showed in particular condition. In dealing with money, competitive recruited staffs think the leaders are not really honest, although in the personal life they seem to be honest.

Differently, non-competitive recruited staff think that the leaders are mostly honest, they think that people should stay positive.

"I think he is good. We just need to stay positive." (Tim, transcript, p. 10)

The same opinion of non-competitive recruited staff also appears in the perception of trust. I think it is influenced by religious values. This is not only because they know the leader well personally, but also because of their belief in having a positive opinion of others. Thus, they 
think that the leaders should be and can be trusted. Living in a country where Muslims are in the majority, civil servants adhere to the values in Holy Quran to avoid immoderate suspicion (Holy Quran 49:12).

On the contrary, competitive recruited staff think that not all leaders can be trusted. This is also related to what they think about the leader's honesty.

"I don't really think so. There were some occasions where he failed to show his integrity... He is not a consistent person either." (Wesley, transcript, p. 39).

Third, communication is very important during interaction. In relation to this aspect, competitive recruited civil servants have a negative perception about their leaders' communication style. This is related to the leader's knowledge about a particular problem. For instance, if the leader knows the substance, communication will always be one-way. On the contrary, if the leader does not understand, he/she tends to be open to two-way communication.

"Yes he does, during the discussion. But sometimes, at a crucial moment, he sets the conclusion before the meeting. He won't listen to our opinion". (Wesley, transcript, p. 39)

Although most non-competitive recruited staff have positive communication with their leaders, one of the interviewees had a similar perception to that of competitive recruited staffs.

"Yes, there is two-way communication. But it only happens when he doesn't know the substance of the issue..." (Evelijn, transcript, $p$. 3)

Additionally, it is not only about the knowledge of the leaders. It is also the leader being too highly qualified that leads negative communication.

"Actually he is dominant, although on many occasions interaction is two-way... It might also be because of his educational level which is too high (doctor), maybe I could not interpret what he wants clearly, so that I cannot follow him as quick as he wants". (Marco, transcript, p. 27)

Competitive recruited staff also think that the leader always listens to them. This is probably because the leader has less knowledge than his/her staff, so that the leader always accept the input.

"Yeah, he is willing to listen and says yes to whatever I say..." (Janneke, transcript, p. 33)

Fourth, as far as reinforcement is concerned, almost all the interviewees feel they have no negative perception about the leaders' way of reinforcing the rules. However, one of the competitive recruited staff does not agree with his/her leader's choice of reinforcement. This appears in following answer:

"By giving more work. This is silly, but he thinks that if his staff work diligently, he rewards them by giving them more work. .... I disagree with that, because he doesn't motivate somebody who is not performing very well, he just will not give them more work. ...". (Marco, transcript, p. 28)

Fifth, the decision-making aspect. This is strongly related to the third aspect about communication. For leaders who always follow the suggestions of their boss, their method of decision-making is not good. This is because the civil servants feel they are excluded from the process. The civil servants also think it is probably because they are new in the field, which makes the leader seem lacking in confidence in deciding something. Competitive recruited staff think that there are leaders who have never made any decisions, or leaders who do not follow up the decisions they have made.

"For example, when we faced the Ransomware threat. The response was really great... However, after the recommendation, there was no followup. We just held a meeting to prevent Ransomware. That's all". (Marco, transcript, $p$. 28) 
"Yes, almost 100\%. As far as I remember, he never made any decisions...". (Janneke, transcript, p. 34)

"Maybe because he is new in this field. He tends to be very careful, I feel he is not really confident in making a decision". (Pamela, transcript, $p$. 37)

"However, I think it was wrong. We still have to monitor the consultation work. We give them a job, then they have to show us how they finish it. We have to set the rules or procedures for that". (Willemin, transcript, p. 43)

Interestingly, civil servants who were recruited non-competitively also think that some leaders should be more independent in making a decision. Sometimes the leaders are not very confident in making a decision and prefer to leave it to their boss.

"I do not really like it. He should have more initiative, he has to be more independent in making decisions. No need to get confirmation from our director". (Tim, transcript, $p$. 11)

"Not really good. I expect him to be more independent". (Ruud, transcript, p. 14)

The five aspects of ethical leadership indicate that, in BIG, competitive recruited staff have negative interaction with their leaders. This is different from the staff who were not recruited competitively. This fact shows that the hypothesis is confirmed, i.e. that competitive recruitment has a negative impact on perception of ethical leadership.

\section{Conclusion}

To sum up, competitive recruitment has negative effect on the perception of ethical leadership. The study shows that competitive recruited staffs are more demanding to their leader. The study also confirmed that different perceptions exist between civil servants who were recruited competitively and those recruited noncompetitively about ethical leadership. Competitive recruited staff have more critics to the leader. The critics appear in the aspect of the leader's personal characteristics, communication, ethical reinforcement, and decision-making. The study confirms the hypothesis that there are negative effects of competitive recruitment on ethical leadership. These critics are due to the low knowledge of the leader, having a different academic background form the field, or if the work relates to money. This perception also shows that competitive recruited staffs are more critical of their leaders. We can say that in the daily basis interaction, these critics could build a negative interaction between the civil servants and their leader. Although some of the non-competitive recruited staff have a critical issue on one particular aspect, overall their perception of their leaders is positive.

The study, however, does have some limitations. For instance, the people compared were either competitive or non-competitively recruited staff. The comparison is based on one person of competitive and of non-competitive recruited staff per one leader. It would be better if the study had covered more people's opinions about interaction with their leaders. This would build a stronger theory. Additionally, in the future, it would be a good idea to link competitive recruitment and effective leadership. The experience of BIG shows that there is an unfair promotion process, thus by correlating the perception of civil servants and effective leadership, such a study would give more insight into organizational management theory.

\section{Acknowledgment}

This research is funded by Lembaga Pengelolaan Dana Pendidikan Republik Indonesia. My gratitude also goes to the blind-reviewers. 


\section{Bibliography}

Bellford, A. (2011, 03 03). In Indonesia, a Scandal Over Soccer. Retrieved 04 03, 2017, from The New York times:

http://www.nytimes.com/2011/03/04/world/asia/04i ht-indonesia04.html

BIG. (n.d.). BIG Selenggarakan Tes CPNS Generasi Pertama. Retrieved 03 10, 2018, from BIG: http://www.big.go.id/big-selenggarakan-tes-cpnsgenerasi-pertama/

Blunt, P., Turner, M., \& Lindroth, H. (2012). Patronage, Service Delivery, and Social Justice in Indonesia. International Journal of Public Administration , 35, 214-220.

Breaugh, J., \& Starke, M. (2000). Research on Employee Recruitment: So Many Studies, So Many Remaining Questions. Journal of Management , 26 (3), 405-434.

Brown, M., Trevino, L., \& Harrison, D. (2005). Ethical Leadership: A social learning perspective for construct development and testing. Organizational Behavior and Human Decision Processes , 97, 117134.
Brown, M. E., \& Treviño, L. K. (2006). Ethical Leadership: A review and future directions. The Leadership Quarterly, 17, 595-616.

Maksum, A. (2014). National Mental and Competitiveness: Transformation Towards Achieving and Progressive Behaviour . Anima, Indonesian Psychology Journal , 29 (2), 63-73.

Tempo. (2013, 09 23). Indonesia, Champions of AFF U-19 2013. Retrieved 04 03, 2017, from Tempo.co:

https://en.tempo.co/read/news/2013/09/23/06851582

9/Indonesia-Champions-of-AFF-U-19-2013

van den Akker, L., Heres, L., Lasthuizen, K., \& Six, F. (2009). Ethical Leadership and Trust" It's All About Meeting Expectation. International Journal of Leadership Studies , 5 (2), 102-122.

Williamson, I., Cable, D., \& Aldrich, H. (2002). How small businesses can overcome barriers to recruitment. In J. A. Katz, \& T. M. Welbourne (Eds.), Managing People in Entrepreneurial Organizations (Advances in Entrepreneurship, Firm Emergence and Growth (Vol. 5, pp. 83-106). Emerald Group Publishing Limited. 